\title{
Evaluation of Mandibular Tooth Supported Over-Denture with Two Different Denture Base Materials
}

\author{
Reham Elshiekh $^{(1)}$, Yasmeen El-Mahdy ${ }^{(2)}$, Dina Kholeif ${ }^{(3)}$
}

Codex : 49/1810

azhardentj@azhar.edu.eg

http://adjg.journals.ekb.eg

\section{KEYWORDS}

Tooth supported over-

denture; thermo-plastic resin;

Electromyography.

\begin{abstract}
Purpose: To compare effect of thermo-plastic and heat cured acrylic denture base materials on electromyography of masseter and temporalis muscles and over-denture abutments in mandibular tooth supported over-denture. Materials and methods: Ten patients having completely edentulous maxillary ridges and mandibular ridges including canines bilaterally were selected. Root canal treatment and abutment preparation were performed to receive copings and over-dentures. Maxillary complete dentures were constructed for all patients. Patients were divided into 2 equal groups. Group I: received mandibular over-denture constructed from thermo-plastic resin for 3 months followed by over-denture constructed from heat-cured acrylic resin for subsequent 3 months. Group II: received mandibular over-denture constructed from heat-cured acrylic resin for 3 months followed by over-denture constructed from thermo-plastic resin for subsequent 3 months. Electromyography and clinical evaluation of abutments were performed at denture insertion, I month and 3 months for every denture.
\end{abstract}

\section{INTRODUCTION}

Over-denture is defined according to the academy of prosthodontic terms as "A removable dental prosthesis that covers and rests on one or more remaining natural teeth, roots and / or dental implants" (1).

"Perpetual preservation of what remains is more important than the meticulous replacement of what is missing "still rings true. Overdenture is a definitely better option as compared to a removable complete denture prosthesis, which certainly has its drawbacks. The use of teeth as support for dentures is aimed at reducing the load on the osseous portions of the denture-bearing area and delay the process of resorption ${ }^{(2)}$.

- Paper extracted from Master Thesis Tilted "Evaluation of Mandibular Tooth Supported Over-denture with Two Different Denture Base Materials".

1. Demonstrator at Prosthodontic Department, Faculty of Dental Medicine For Girls, Al-Azhar University.

2. Assistant Professor at Prosthodontic Department, Faculty of Dental Medicine For Girls, Al-Azhar University. 
An abutment root or tooth must be chosen that is surrounded by healthy periodontal tissues. The tissues may already be healthy or treated by appropriate periodontal therapy. Compromised teeth with a good treatment prognosis are generally regarded as suitable candidates even when horizontal bone loss is present. Conversely, significant vertical bone loss, particularly if accompanied mobility, often precludes a tooth selection ${ }^{(3)}$.

The teeth the most suitable for over-denture concept are the canines. These are the teeth the most richly innervated with sensory receptors and they are often the last ones remaining in the $\operatorname{arch}^{(4)}$.

The use of coping is recommended by many authors to confirm to the proper abutment height, to create proper abutment contour and angulations, to provide protection against caries, to restore and reinforce broken down endodontically treated abutments, to obtain excellent psychological results ${ }^{(5)}$.

The use of thermoplastic resins has been widely used due to their outstanding characteristics. Their continuous progression allows new classes of more developed materials and technologies, that increase the possibility of manufacturing dentures with better splinting properties compared to the conventional dentures ${ }^{(6)}$.

It was stated that thermoplastic resins are used for a broad variety of applications from removable thermo-plastic partial dentures, performed partial denture clasp, fiber reinforced fixed partial dentures, provisional crowns and bridges, obturators and speech therapy appliances, orthodontic retainers and brackets, impression trays and border molding materials, occlusal splints, sleep apnea appliances, and implant abutments ${ }^{(7)}$.

Electromyography is defined as the graphic recording of the electrical potential of muscles. It has been the only tool used to assess the muscle activity of the stomatognathic system. Electromyography (EMG) is used for the study of bioelectric phenomena that occur in muscle fibers during rest, stress and maximum contraction.
Electrodes are placed overlying the muscle to be evaluated, which capture the sum of the electrical activity of all activated muscle fibers. The EMG has been widely used by physicians, speech therapists and professionals in physical education for the study of human motions ${ }^{(8)}$.

Periodontal diseases have been historically considered the most important oral health concerns. Dental prosthesis may influence the periodontal condition, the risk of caries and amount of stress on natural teeth. Continuing surveillance of levels and risk factors of periodontal disease is one of the basic functions to planning and evaluating preventive activities and oral health promotion ${ }^{(9)}$.

Tooth mobility has been considered and investigated as an indirect measure of the functional condition of the periodontium. Tooth mobility is considered to be of paramount significance of establishment of diagnosis, prognosis and treatment plan. This may be performed by the large number of devices and methods of tooth mobility assessment that have been developed and tested ${ }^{(10)}$.

It was stated that gingival crevicular fluid is an- inflammatory exudates that flows from the gingival sulcus or periodontal pockets. The quantity of gingival crevicular fluid flowing from a site is influenced not only by the degree of inflammation in the tissues but also by the extent of ulceration of the sulcular/pocket epithelium ${ }^{(11)}$.

Visual signs (redness, swelling, and change in texture) and/or presence of marginal bleeding have been included as components used for the diagnosis of gingivitis. One gingival index that is widely used today is the Loe and Silness gingival Index. This index has proved useful in controlled clinical trials because it is fairly sensitive to small changes, is simple to administer, permits calibration of the examiners to minimize inter- and intra examiner error ${ }^{(12)}$.

When sulcular depth is chronically in excess of three millimeters, food debris and microbes accumulate. This poses a danger to periodontal 
ligaments that attach gingival to the tooth causing periodontal pocket. For over-denture abutments, progression of their pocket depth is influenced by several factors including cigarette smoking, diabetes mellitus and irregular attendance at dental clinic ${ }^{(13)}$.

This study aimed to evaluate effect of mandibular tooth supported over-denture with thermo-plastic and heat cured denure base materials on electromyographic activity of masseter and temporalis muscles and clinical evaluation of abutments.

\section{MATERIAL AND METHODS}

Ten patients of age ranging from 55 to 65 years were selected from the clinic of the Removable Prosthodontics Department. Inclusion criteria for enrollement were; Patients had completely edentulous maxilla against two mandibular healthy canines with healthy periodontal attachment, adequate alveolar bone support and crown/root ratio not less than $1: 1$ as verified by periapical radiograph. They also have sufficient interocclusal distance and normal ridge relationship and patients with good bony support around canines.

Conventional steps of tooth supported overdenture including endodontic treatment, primary impression, coping cementation, final impressions, maxilla-mandibular relationship registration and try in stage were performed for all patients. Fig. (1).

All patients received maxillary heat cured acrylic dentures. Patients were equally grouped into 2 groups, each group included 5patients. Group I: Patients received mandibular thermoplastic acrylic over-denture, for 3 months followed by receiving mandibular heat-cured acrylic over-denture for subsequent 3 months. Group II: Patients received mandibular heat cured acrylic over-denture for 3 months followed by receiving mandibular thermoplastic acrylic over-denture for subsequent 3 months. The second denture in both groups was manufactured on the duplicated cast.
Electromyographic activity records were obtained at denture insertion, one month and after three months of denture insertion. For all of the patients the action potential representing the electrical activity of the right and left masseter and anterior fibers of temporalis muscles was recorded by means of electromyography while the lower denture takes only support from the dome shape mandibular canines. Fig. (2).

Clinical evaluation of abutments including tooth mobility, gingival index, pocket depth and crevicular fluid flow was done for each patient at the time of denture insertion, one month and after three months of denture insertion.

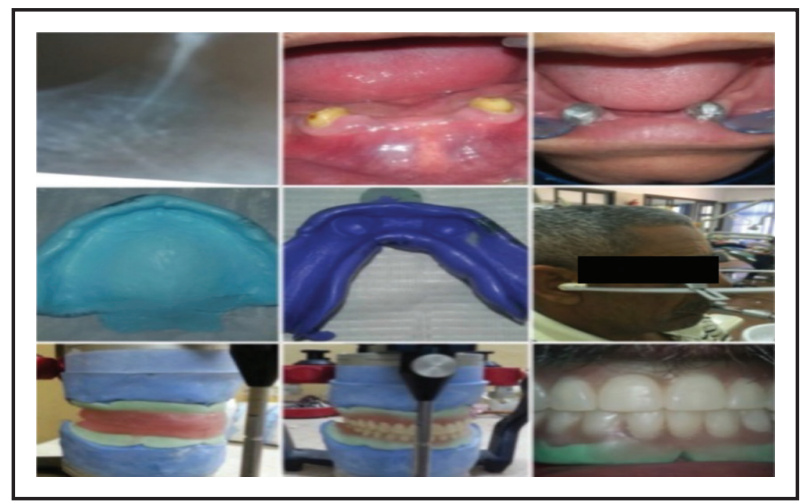

Figure (1): Conventional steps of tooth over-denture construction.

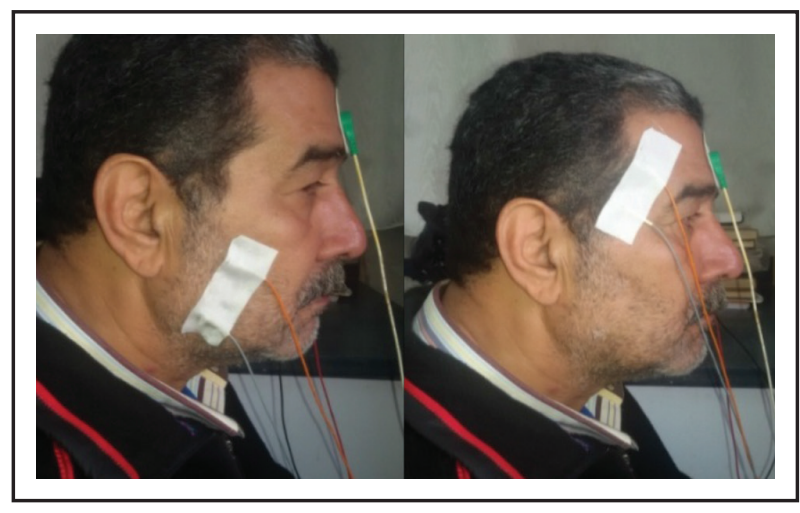

Figure (2): Electromyographic evaluation for masseter and temporalis muscles. 


\section{RESULTS}

For masseter muscle, using soft food, a higher mean value was recorded in group II, with a significant difference. In the $5^{\text {th }}$ record, a higher mean value was recorded in group II, with no significant difference. However, in the last record, higher mean value was recorded in group I, with no significant difference. Using hard food, a higher mean value was recorded in group II, with a significant difference. In the $4^{\text {th }}$ record, a higher mean value was recorded in group II, with no significant difference. In the $5^{\text {th }}$ record, a higher mean value was recorded in group I, with no significant difference. Moreover, in the last record, higher mean value was recorded in group I, with a significant difference (Table 1).

For temporalis muscle using soft food, a higher mean value was recorded in group II, with a significant difference in the $1^{\text {st }}, 2^{\text {nd }}$ records. In the $4^{\text {th }}$, $5^{\text {th }}$ and $6^{\text {th }}$ records, a higher mean value was recorded in group I, with no significant difference in the $4^{\text {th }}$ record, and a significant difference in the $5^{\text {th }}$ and $6^{\text {th }}$ records. Using hard food, a higher mean value was recorded in group II, with a significant difference. In the $4^{\text {th }}$ record, a higher mean value was recorded in group II, with no significant difference. However, in the $5^{\text {th }}$ record, a higher mean value was recorded in group I, with significant difference. Moreover, in the last record, higher mean value was recorded in group I, with a significant difference (Table 2).

For all patients, clinical evaluation of abutments including tooth mobility, gingival index, pocket depth and crevicular fluid flow were performed at 0,1 month and 3 months intervals for each type of over-denture base. The results of clinical evaluation of abutments showed no significant increase in pocket depth, gingival index, tooth mobility and crevicular fluid flow reaching the maximum at the end of follow up period between both types of overdenture bases (Figs. 3, 4, 5, 6).

Table (1): Comparison of EMG activity of masseter muscle in both groups:

\begin{tabular}{|c|c|c|c|c|c|c|c|}
\hline \multirow{2}{*}{ Groups } & \multirow{2}{*}{ Records } & \multicolumn{2}{|c|}{ Group I } & \multicolumn{2}{|c|}{ Group II } & \multirow{2}{*}{$\mathbf{T}$} & \multirow{2}{*}{$\mathbf{P}$} \\
\hline & & Mean & SD & Mean & SD & & \\
\hline \multirow{6}{*}{ Soft food } & $1^{\text {st }}(0$ record $)$ & 84.10 & 27.64 & 216.26 & 75.09 & 5.22 & $0.00 *$ \\
\hline & 2nd (1 month) & 48.26 & 15.71 & 157.06 & 57.48 & 6.38 & $0.00 *$ \\
\hline & $3^{\text {rd }}$ (3 months) & 51.46 & 17.41 & 149.86 & 41.18 & 7.61 & $0.00 *$ \\
\hline & $4^{\text {th }}(0$ record $)$ & 71.77 & 14.75 & 134.45 & 41.94 & 3.62 & $0.02 *$ \\
\hline & $5^{\text {th }}$ (1 month $)$ & 82.58 & 20.98 & 99.17 & 30.83 & 1.41 & $0.176 \mathrm{~ns}$ \\
\hline & $6^{\text {th }}$ (3 months) & 93.73 & 23.03 & 87.47 & 30.86 & 0.51 & $0.6134 \mathrm{~ns}$ \\
\hline \multirow{6}{*}{ Hard food } & $1^{\text {st }}(0$ record $)$ & 119.04 & 41.39 & 249.27 & 81.25 & 7.12 & $0.00 *$ \\
\hline & 2nd (1 month) & 110.20 & 38.07 & 189.30 & 63.72 & 3.13 & $0.00 *$ \\
\hline & $3^{\text {rd }}$ (3 months) & 84.23 & 30.76 & 163.18 & 52.50 & 4.43 & $0.00 *$ \\
\hline & $4^{\text {th }}(0$ record $)$ & 153.78 & 51.98 & 155.65 & 31.65 & 0.71 & $0.83^{\mathrm{ns}}$ \\
\hline & $5^{\text {th }}$ (1 month) & 155.41 & 56.54 & 123.92 & 30.34 & 1.55 & $0.1381^{\mathrm{ns}}$ \\
\hline & $6^{\text {th }}$ (3 months) & 168.58 & 55.58 & 112.63 & 33.27 & 2.73 & $0.0137 *$ \\
\hline
\end{tabular}

Significance level $p<0.05$, * significant, $n s=$ non-significant . 
Table (2): Comparison of EMG activity of temporalis muscle in both groups:

\begin{tabular}{|c|c|c|c|c|c|c|c|}
\hline \multirow{2}{*}{ Groups } & \multirow{2}{*}{ Records } & \multicolumn{2}{|c|}{ Group I } & \multicolumn{2}{|c|}{ Group II } & \multirow{2}{*}{$\mathbf{T}$} & \multirow{2}{*}{$\mathbf{P}$} \\
\hline & & Mean & SD & Mean & SD & & \\
\hline \multirow{6}{*}{ Soft } & $1^{\text {st }}(0$ record $)$ & 118.43 & 24.65 & 175.54 & 61.65 & 6.19 & $0.00 *$ \\
\hline & 2nd (1 month) & 88.05 & 32.97 & 167.89 & 58.39 & 8.15 & $0.00 *$ \\
\hline & $3^{\text {rd }}$ (3 months) & 93.09 & 21.79 & 100.16 & 31.28 & 3.28 & $0.67 \mathrm{~ns}$ \\
\hline & $4^{\text {th }}(0$ record $)$ & 102.18 & 24.59 & 95.76 & 16.97 & 0.95 & $0.53 \mathrm{~ns}$ \\
\hline & $5^{\text {th }}$ (1 month $)$ & 114.10 & 28.93 & 83.25 & 9.92 & 3.19 & $0.005^{*}$ \\
\hline & $6^{\text {th }}$ (3 months) & 146.07 & 47.99 & 72.97 & 9.36 & 3.96 & $0.00 *$ \\
\hline \multirow{6}{*}{ Hard } & $1^{\text {st }}(0$ record $)$ & 137.75 & 27.83 & 222.41 & 71.91 & 5.17 & $0.00 *$ \\
\hline & 2nd (1 month) & 119.20 & 28.09 & 207.07 & 63.09 & 3.94 & $0.00 *$ \\
\hline & $3^{\text {rd }}$ (3 months) & 86.80 & 27.63 & 155.48 & 44.54 & 4.67 & $0.00 *$ \\
\hline & $4^{\text {th }}(0$ record $)$ & 122.45 & 28.46 & 133.33 & 26.75 & 0.73 & $0.53 \mathrm{~ns}$ \\
\hline & $5^{\text {th }}$ (1 month $)$ & 153.41 & 54.24 & 119.02 & 19.18 & 3.02 & $0.046^{*}$ \\
\hline & $6^{\text {th }}$ (3 months) & 184.66 & 59.30 & 103.40 & 11.48 & 6.47 & $0.00 *$ \\
\hline
\end{tabular}

Significance level $P<0.05$, * significant, $n s=$ non-significant.

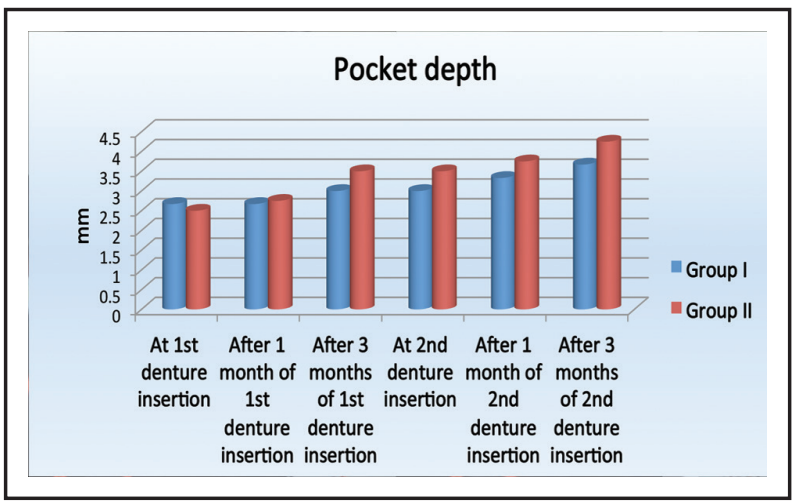

Figure (3) Column chart illustrates Pocket depth ( $\mathrm{mm}$ ) in both groups.

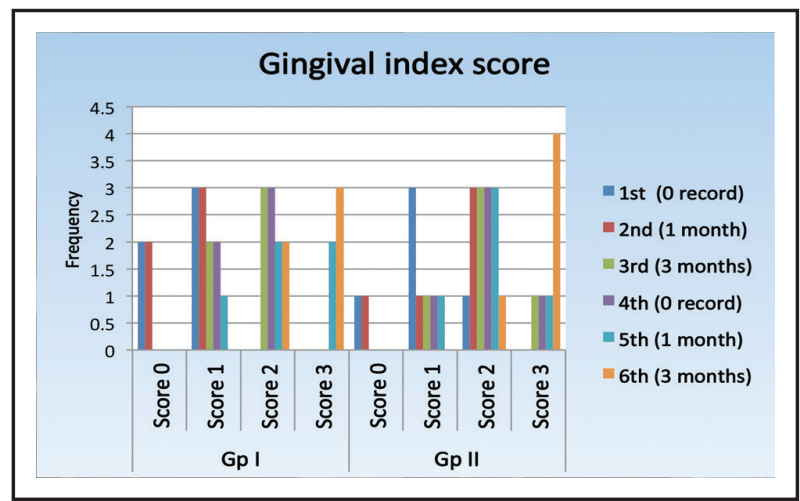

Figure (4) Column chart illustrates gingival index scores in both groups. 


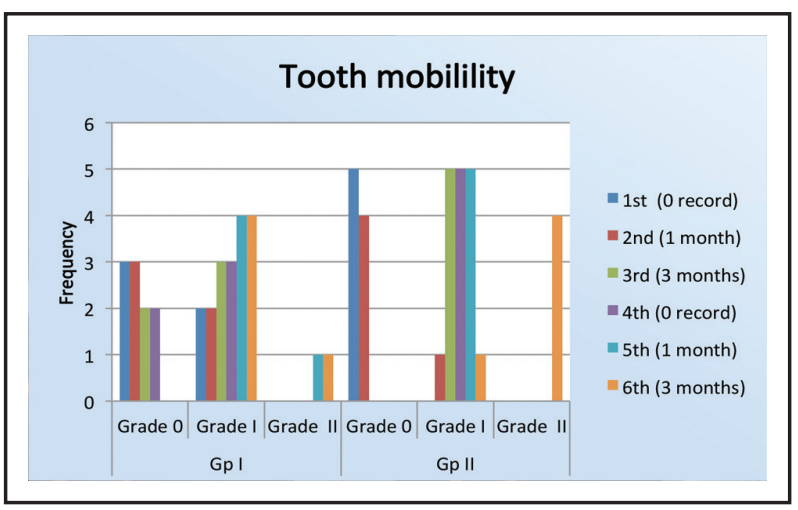

Figure (5) Column chart illustrates tooth mobility scores in both groups.

\section{DISCUSSION}

All the selected patients had two remaining canines. The reason for canines being used in this study is that they exhibit characteristics associated with support. This occurs because of their long triangular roots with greater periodontal area for attachment and wider attached epithelium ${ }^{(14)}$. Short copings were planned in this study to improve stability, preserve the alveolar bone and maintain properioception because there was no additional retention required ${ }^{(15)}$.

Although the heat-cured acrylic resin is the most popular denture base material, this study used the thermoplastic resin to construct mandibular over-denture supported by two remaining canines. Thermoplastic resin is a biocompatible material with unique physical and esthetic properties ${ }^{(16)}$.

The superficial masseter and anterior fibers of the temporalis muscles were selected to represent the masticatory muscle activity because they are the largest and strongest masticatory muscles and thus, have a major role in mandibular movement ${ }^{(17)}$.

Gingival index was measured according to Löe and Silness. It was created for precise assessment of the gingival condition and records qualitative changes in the gingiva ${ }^{(18)}$. In addition, the severity of periodontal diseases was precisely assessed through measuring periodontal pocket depth

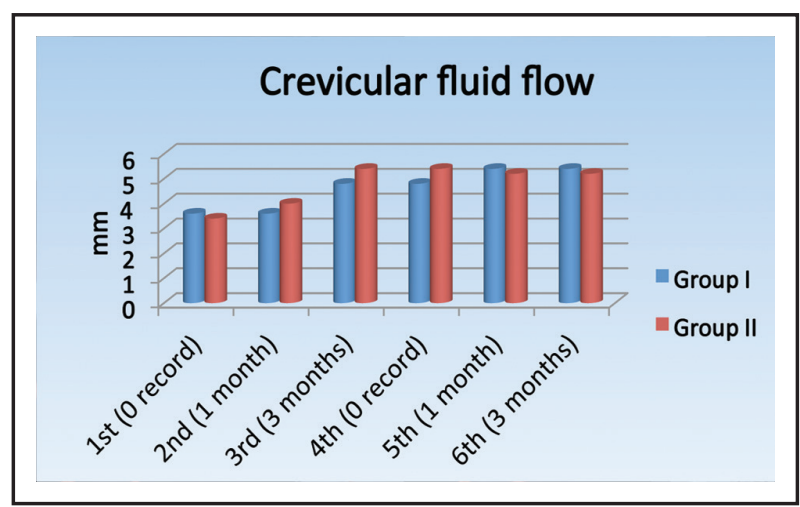

Figure (6) Column chart illustrates crevicular fluid flow (mm) in both groups.

with a periodontal probe (Williams markings) ${ }^{(19)}$. Moreover, tooth mobility was measured using Miller classification which is usually graded from 0 to 3 because it is widely used in the choice of diagnosis, treatment and prognosis prediction ${ }^{(20)}$. Gingival crevicular fluid (GCF) was measured according to Loe and Holm-Pedersen technique. Filter paper strips were placed in the gingival crevice until resistance was felt. The wetted area with GCF became more visible by staining with ninhydrin stain ${ }^{(21)}$.

When comparing group I and group II, it was found that after first over-denture insertion, the mean values of masseter and temporalis muscles were decreased through the follow up period regardless type of over-denture base. This is in accordance with study that reported improvement of EMG activity by time because improving denture adaptation which may be due to the neuromuscular control which is gradually and slowly generated by time, i.e. the longer the period of denture wearing, the better the neuromuscular control gained ${ }^{(22)}$.

When comparing both groups, there was a non significant increase in pocket depth, gingival index and tooth mobility. Most of these changes were nearly close to each other in both groups reaching its maximum at the end of follow up period regardless type of denture base. These results are in accordance with a study that stated that the material of denture 
base is not a factor in the mouth reactions. This is supported by clinical observation that duplicating the denture into different material does not relieve the symptoms e.g. chronic denture stomatitis ${ }^{(23)}$.

Regarding crevicular fluid flow, there was slight significant increase in crevicular fluid flow with each group reaching its maximum at the end of follow up period. This may be related to insertion of overdenture into the patient mouth and subsequently leading to change in the ecology and the abutment teeth become situated media ${ }^{(24)}$.

\section{CONCLUSION}

With limitation of this study it could be concluded that,the use of thermo-plastic resin as over-denture base caused improving in electromyographic activity regardless the time of its insertion. Heat cured denture caused improvement in electromyographic activity when it is only inserted firstly. There was no clear difference between the effect of both types of denture bases on clinical evaluation of abutments including pocket depth, tooth mobility, gingival index and crevicular fluid flow.

\section{REFERENCES}

1- Academy of Prosthodontic Terms. J Prosthet Dent 2005; 21: 94.

2- Dhir RC. Clinical Assessment of Over-denture Therapy. J Indian Prosthodont Soc 2005; 5: 187- 192.

3- Brewer AA, Morrow RM. Over-denture $2^{\text {nd }}$ ed. C.V. Mosby Co; St. Louis, London 1980; 31: 364.

4- Wolfart S, Haselhuhn K, DerksA,Von der Gracht. EMG Correlations of Edentulous Patients with Implant Over-dentures and Fixed Dental Prosthesis Compared to Conventional Complete dentures and Dentates. A Systematic Review and Meta- analysis. Clin Oral Impl Res 2017; 28: 765-773.

5- Porwal A. Prosthodontic Treatment for Edentulous Patients: Complete Dentures and Implant-Supported Prosthesis. Int J Prosthet Dent 2010; 18: 17-29.

6- Shivani K, Shekhar B. Polyamides in Dentistry. Int J Scient Study 2013, 1:10-17.
7- Negrutiu M, Sinescu C, Romanu M, Pop D, Lakatos S. Thermoplastic Resins for Flexible Framework Removable Partial Dentures. Timisoara Med J 2005; 55: 295-99.

8- Kuriki HU, De Azevedo FM, Takahashi LS, Mello EM, Filho RN, Alves N. The Relationship between Electromyography and Muscle Force.EMG Methods for Evaluating Muscle and Nerve Function (2012), Mr. Mark Schwartz (Ed), ISBN: 953-78.

9- Moimaz SA, Saliba NA, Saliba O, Bolonhez MR, Zina LG. Association between Dental Prosthesis and Periodontal Disease in A rural Brazilian Community. Braz J Oral Sci 2006; 19: 1226-1231.

10- Banavali KA, Chitnis P, Upadhye K, Kotak B. Compatative Evaluation of Reduction in Tooth Mobility Using Periotest? In Lower Anterior Teeth Post Phase, Therapy in Patients with Mild to Moderate Gingivitis: A randomized Controlled Trial. Int J Current Res 2014; 11: 87.

11- Griffith GS. Formation, Collection and Significance of Gingival Crevice Fluid. Periodontol 2000 2003; 31:32- 42.

12- Parab P, Aspalli S, Devarathnamma MV, Nagappa G, Archana D, Shetty S. Evaluation of Antiplaque and Antigingivitis Effect of Herbal Mouthwash in Treatment of Plaque Induced Gingivitis: A randomized, Clinical Trial. J Indian Soc Periodontol 2014; 1: 48- 52.

13- Hirotomi T, Yoshihara A, Ogawa H, Miyazaki $H$. Tooth-related Risk Factors for Periodontal Disease in Community-dwelling Elderly People. J Clin Periodontol 2010; 37: 494- 500 .

14- Jayasree K, Bharathi M, Nag VD, Vinod B: Precision attachment: Retained over-denture. J Indian Prosthodont Soc. 2012; 12: 59-62.

15- Verma P, Kalra NM, Garg S: Conventional Tooth Supported Over-dentures -Case Report: Solutions for Challenging Situations. Indian J Dent 2014; 6: 61-63.

16- Bidkar DS, Hazari P, Bhoyar A, Agarwal S: Flexible Overdenture: A Clinical Case Report. IJCD.2011; 4: 88- 91.

17- Nassani MZ, Ibraheem EM. The Effect of Flexible Acrylic Resin on Masticatory Muscle Activity in ImplantSupported Mandibular Over-denture. Electronic Physician 2016; 8: 1752-58.

18- Panagakos FS, Davies RM. Gingival Diseases: Their Aetiology, Prevention and Treatment. InTech, Croatia 2011; 43: 42-54 
19- Chang JF, Yeh JC, Liou JC, Hsiung JR, Tung TH. Periodontal Pocket Depth, Hyperglycemia, and Progression of Chronic Kidney Disease: A Population-Based Longitudinal Study. Am J Med 2017; 130: 61- 69.

20- Erhabor P,Azodo CC. Management of Tooth Mobility in the Periodontology Clinic: An Overview and Experience from A tertiary Healthcare Setting. AJMHS 2016; 15: 50-57.

21- Umoh AO, Ize-lyamu IN. Gingival Crevicular Fluid Volume, Blood Pressure and Blood Sugar in Adult Females with Malocclusion in Benin City, Nigeria. Port Harcourt
Medical Journal 2017; 11: 72-78.

22- Mesallati SA, Saba EKA, Abd El Aziz O. Masticatory Efficiency of Complete Dentures Constructed by Different Denture Base Materials. IJSR 2016; 5: 1292-99.

23- Anusavice KJ. Philip Science of Dental Material $10^{\text {th }} \mathrm{Ed}$. W B. Sounders comp, London Toronto 1996.

24- Zasshi KG, Ichikawa K. Influence of Covering Gingival Sulcus with Denture Base on Periodontal Tissue PH Value in gingival sulcus and amount of Gingival Crevicular Fluid. Japanese J 1998; 65: 100- 111. 